\title{
Current control of distributed generation power inverters for losses reduction in the distribution network
}

\author{
E. Belenguer, H. Beltran, N. Aparicio, E. Pérez \\ Department of Engineering of Industrial Systems and Design \\ Universitat Jaume I de Castelló \\ Campus de Riu Sec, E-12071 Castelló de la Plana (Spain) \\ Phone: +34 964 728178, Fax: +34 964728170 , \\ e-mail: efbeleng@esid.uji.es, hbeltran@esid.uji.es, aparicio@esid.uji.es, ,pereze@esid.uji.es
}

\begin{abstract}
The main objective of the paper is to evaluate the power losses reduction that can be achieved in a low voltage distribution network when the inverters associated to the distributed generation are used as active power filters to compensate the non active currents produced by inductive and unbalanced loads. For that purpose, a hysteresis current control has been proposed and implemented. A real distribution threephase four-wire network has been simulated considering a large penetration of distributed generation. Power losses and the efficiency of the network have been quantified for different compensation cases.
\end{abstract}

\section{Key words}

Distributed generation, active power filters, losses minimization, current control of inverters.

\section{Introduction}

Distributed Generation (DG) is expected to grow significantly in the future [1], [2]. Environmental concerns and national requirements for a more efficient use of the energy are boosting the deployment of renewable energy sources and combined heat and power units in the low voltage electrical system level. These distributed generators are characterized mainly by their unplanned location and by a reduced nominal power (under $1 \mathrm{MW}$ ). In most of the systems, a three-phase Voltage Source Inverter (VSI) is used to link the DC or variable frequency $\mathrm{AC}$ output of the generator with the fixed frequency AC network.

It is known that a large penetration of DG may produce different technical problems related to the performance and control of the bulk power system [3]. On the other hand, the use of power electronics for the interfacing with the network allows the implementation of different management functions that can enhance the performance of the distribution network.
Usually, the VSI associated to distributed generators are programmed to maximize the active current and, consequently, the active power supplied to the network. However, a current control mode of the VSI can expand its control possibilities allowing the implementation of the following operation and control functions:

- Reactive power compensation

- Voltage control through active/reactive power control

- Frequency control through active power control

- Compensation of asymmetric current components

- Voltage unbalance compensation

- Current harmonics compensation

For that purpose, the VSI must control the currents injected at the point of common coupling (PCC) where the DG is connected to the network (Fig.1).

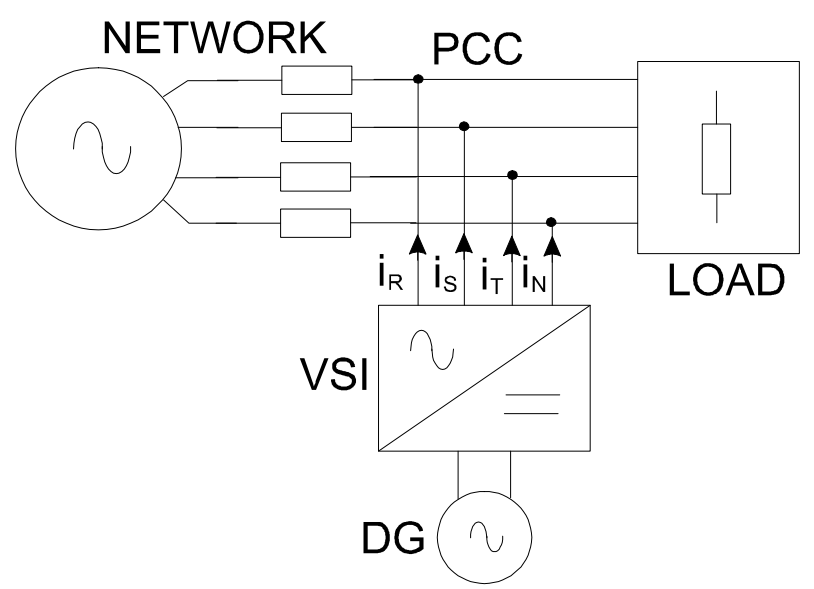

Fig. 1. Scheme of a low voltage network with DG

In this paper, an independent hysteresis controller for each of the phase currents is proposed as the best method to implement the functions listed above. A real 
distribution low voltage network has been simulated and tested in order to evaluate the reduction in the network losses that can be achieved when the VSI associated to the DG are used as active power filters (APF) to compensate the non active currents required by inductive and unbalanced loads.

\section{Power losses in low voltage distribution networks}

Low voltage networks are usually three-phase four-wire systems where both, three-phase and single-phase loads are connected. As a consequence, these networks do not work in completely balanced conditions. Power losses in a three-phase four-wire line can be found as:

$$
P_{L}=R_{L}\left(I_{R}^{2}+I_{S}^{2}+I_{T}^{2}\right)+R_{N} I_{N}^{2}
$$

where $R_{L}$ and $R_{N}$ are, respectively, the resistances of the line and neutral wires. Assuming sinusoidal conditions and using symmetrical components, the above equation can be transformed into:

$$
P_{L}=3 R_{L}\left(I_{+}^{2}+I_{-}^{2}+I_{0}^{2}\right)+9 R_{N} I_{0}^{2}
$$

where $I_{+}, I_{-}$and $I_{0}$ are respectively the modules of the positive, negative and zero sequence components of the three-phase currents $\bar{I}_{R}, \bar{I}_{S}$ and $\bar{I}_{T}$. Aditionally, we may decompose the positive sequence component $\bar{I}_{+}$in two orthogonal components, the active current $\bar{I}_{a}$ and the reactive current $\bar{I}_{r}$. This gives:

$$
P_{L}=3 R_{L}\left(I_{a}^{2}+I_{r}^{2}+I_{-}^{2}+I_{0}^{2}\right)+9 R_{N} I_{0}^{2}
$$

And finally, we may consider that the neutral wire resistance is two times the line wire resistance which is a common characteristic of many low voltage distribution systems. In that case, equation (3) becomes:

$$
P_{L}=3 R_{L}\left(I_{a}^{2}+I_{r}^{2}+I_{-}^{2}+7 I_{0}^{2}\right)
$$

The maximum efficiency in the power system is achieved when all the voltages and the currents in the system are sinusoidal and balanced and the reactive power consumed by the loads is totally compensated. In that case:

$$
P_{L}=3 R_{L} I_{a}^{2}
$$

Consequently, to reach maximum efficiency in the distribution network the non active components of the current, i.e. the reactive, negative sequence and zero sequence components must be cancelled.

\section{Distributed inverter systems as active power filters}

Equation (4) shows that to achieve maximum efficiency in the distribution system it is necessary to compensate the non active components of the current, including the zero sequence component. The traditional topology used for DG applications, the Three-Leg Full Bridge inverter, is not valid for the compensation of the zero sequence current component as there is no connection with the neutral wire.

In order to work as APF and allow unbalance compensation, different inverter topologies have been defined and analysed for different applications [4]. In this paper a Three-Bridge Four-Wire (TBFW) configuration has been used as shown in Fig.2. Its main advantage is that it can be considered composed of three independent single-phase inverters.

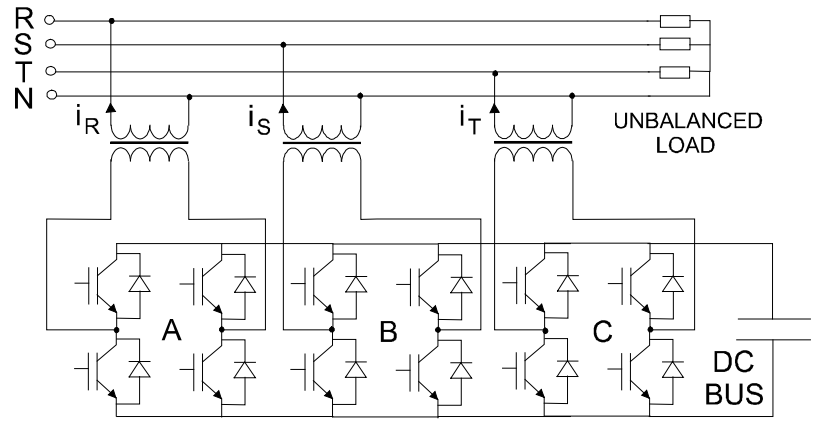

Fig. 2. Three-Bridge Four-Wire VSI topology

This kind of topology allows the injection of reactive currents at the PCC to compensate the inductive behaviour of the load. At the same time, the inverter can act as a power redistribution unit supplying the negative and zero sequence currents demanded by the unbalanced load so the whole (inverter + load) can be seen as a resistive balanced load. To compensate all the non active currents consumed by the load, the VSI should inject into the PCC the following currents:

$$
\begin{gathered}
\bar{I}_{R}=\bar{I}_{r}+\bar{I}_{-}+\bar{I}_{0} \\
\bar{I}_{S}=a^{2} \bar{I}_{r}+a \bar{I}_{-}+\bar{I}_{0} \\
\bar{I}_{T}=a \bar{I}_{r}+a^{2} \bar{I}_{-}+\bar{I}_{0}
\end{gathered}
$$

being $\bar{I}_{-}$and $\bar{I}_{0}$ respectively, the negative and zero sequence components of the load current and $\bar{I}_{r}$ the reactive component of the positive sequence current.

According to equation (4), the zero sequence component should be the first one to be compensated as its related power losses term is multiplied by the highest coefficient. The reduction of one unit of the zero sequence component produces a losses decrease seven times higher than the reduction of one unit of the negative sequence or the reactive component. 
It has to be taken into account that the main objective of the DG is to supply active power to the system. However, most of the DG units use their nominal power during just a small fraction of the time (wind generators, photovoltaic systems) or they may have an intermittent operation (CHP plant) so the remaining power capacity can be used to carry out some of the compensation functions proposed.

\section{Current control of the inverters}

In order to compensate those current components not desired in the system it is necessary to provide a current control mode for the inverters. As shown in Fig. 3 three independent hysteresis controllers have been implemented to allow for the control of each phase current. The current in the neutral wire is naturally determined by the Kirchhoff current law. The main advantages of this control system are a high dynamic behaviour, a natural control and a simple implementation compared to other types of controllers [5], [6].

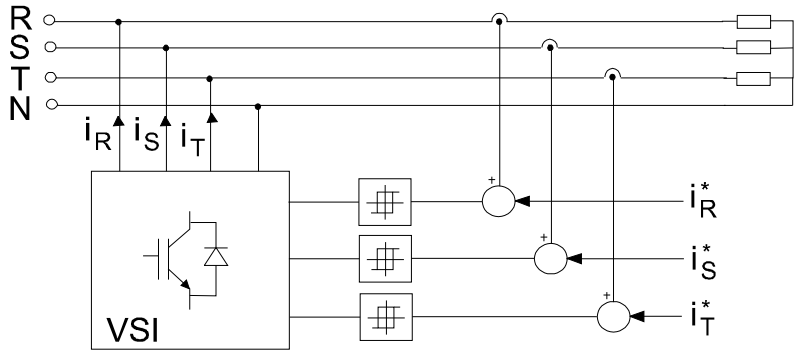

Fig. 3. Hysteresis control system

According to Fig.3, the three load phase currents are measured and the three reference currents are created depending on the current components that are to be compensated. When the error of one of the phases equals the upper limit of the tolerance band, the corresponding IGBTs are switched on to increase the current in that phase and when it reaches the lower limit then the IGBTs are switched off to decrease the current. The switching frequency will be variable over the fundamental period since the current ripple is determined by the hysteresis band. An adaptive band can be designed in order to obtain a fixed switching frequency [7].

\section{Low voltage distribution network}

A real low voltage distribution network has been simulated using the Matlab/Simulink/SimPowerSystems library. A VSI has been connected in parallel with each load in order to fully evaluate the benefits in losses reduction when compensating all the non active current components in the network. The network has a typical urban configuration. The complete system is composed of, as shown in Fig.4, two $400 \mathrm{kVA}$ transformers supplying nine independent underground feeders and a total of 14 loads.

The loads are considered to be constant impedances. The values of these impedances are established through the definition of their nominal power and nominal voltage. The powers consumed by the different loads have been distributed into the three phases in order to simulate realistic voltage unbalances. Table I shows the nominal powers defined for the loads. All the loads have a constant 0.8 lagging power factor.

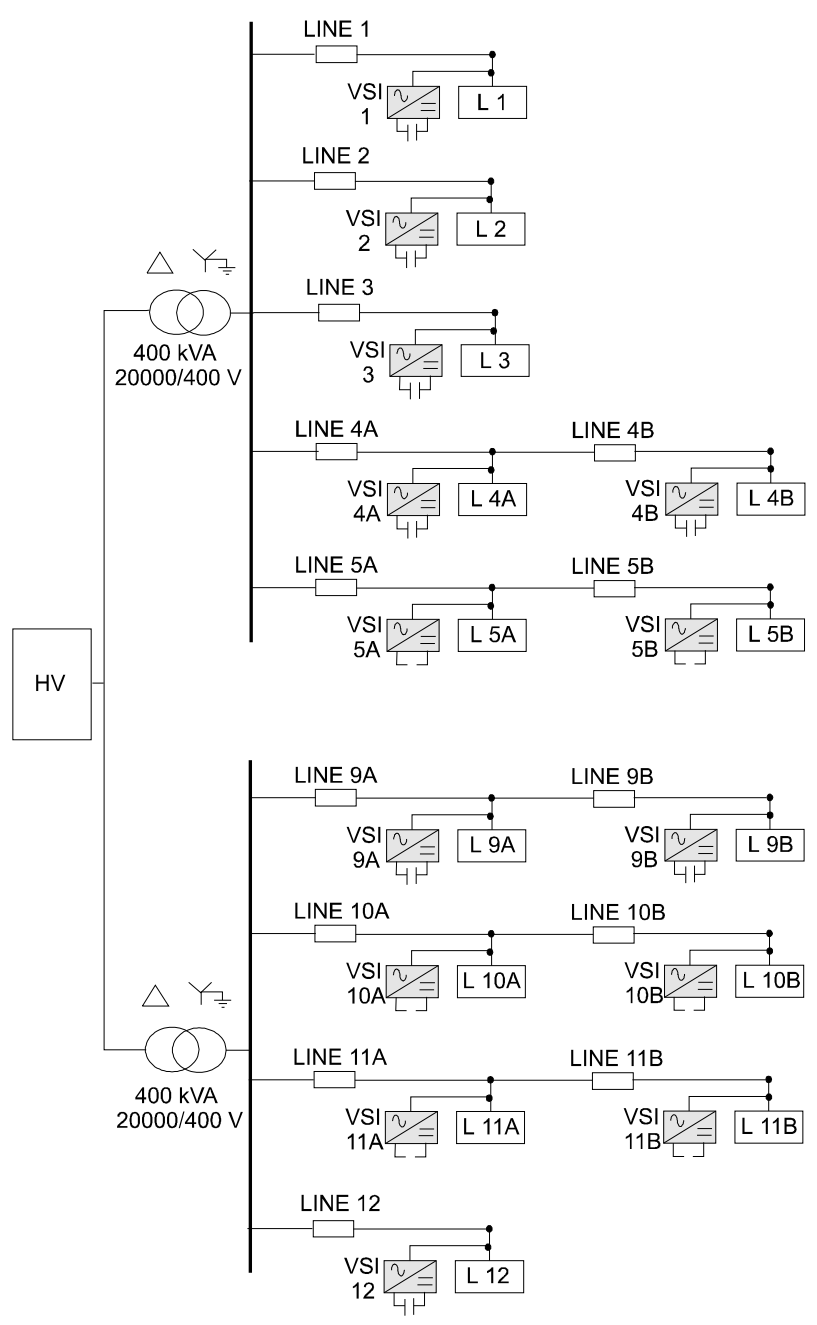

Fig. 4. Low voltage distribution network

Network elements characteristics and system impedances are shown in Tables II and III. Electrical lines are composed of aluminium conductors being the neutral wire section approximately one half of the line wire section.

For the sake of simplicity, all the VSI are supposed to have a nominal power of $50 \mathrm{kVA}$ what gives a nominal current of $72 \mathrm{~A}$. 


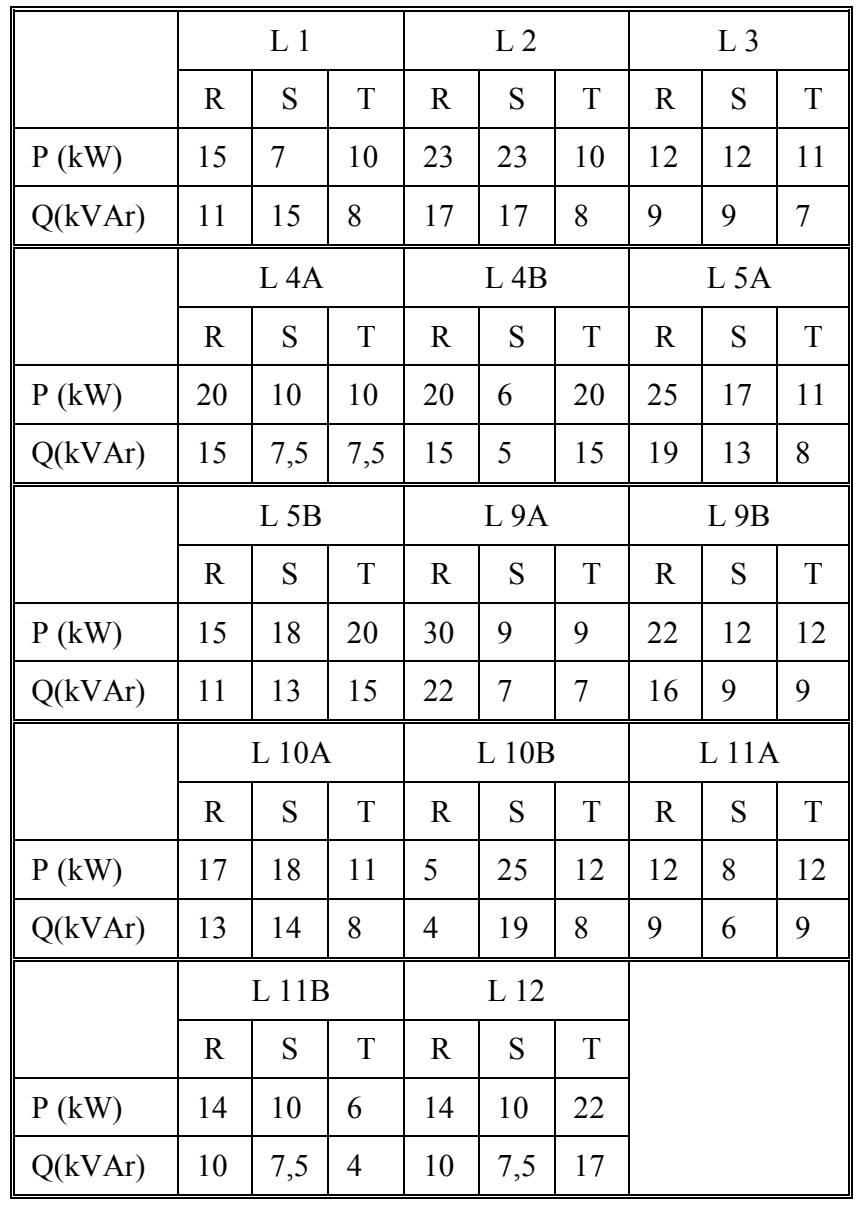

\begin{tabular}{|c|c|c|c|c|c|c|c|c|}
\hline & \multirow{2}{*}{\multicolumn{2}{|c|}{ Transf. }} & \multicolumn{2}{|c|}{ L1 } & \multicolumn{2}{|c|}{ L2 } & \multicolumn{2}{|c|}{ L3 } \\
\hline & & & $\mathrm{Ph}$ & $\mathrm{N}$ & $\mathrm{Ph}$ & $\mathrm{N}$ & $\mathrm{Ph}$ & $\mathrm{N}$ \\
\hline $\mathrm{R}(\mathrm{m} \Omega)$ & \multicolumn{2}{|c|}{4.3} & 4.5 & 8.6 & 6.7 & 10.5 & 3.8 & 6 \\
\hline \multirow[t]{3}{*}{$\mathrm{X}(\mathrm{m} \Omega)$} & \multicolumn{2}{|c|}{14.9} & 1.1 & 0 & 1.7 & 0 & 0.9 & 0 \\
\hline & \multicolumn{2}{|c|}{$\mathrm{L} 4 \mathrm{a}$} & \multicolumn{2}{|c|}{$\mathrm{L} 4 \mathrm{~b}$} & \multicolumn{2}{|c|}{ L5a } & \multicolumn{2}{|c|}{ L5b } \\
\hline & $\mathrm{Ph}$ & $\mathrm{N}$ & $\mathrm{Ph}$ & $\mathrm{N}$ & $\mathrm{Ph}$ & $\mathrm{N}$ & $\mathrm{Ph}$ & $\mathrm{N}$ \\
\hline $\mathrm{R}(\mathrm{m} \Omega)$ & 7.1 & 14.3 & 2.4 & 4.8 & 14.9 & 29.8 & 2.6 & 5.2 \\
\hline \multirow[t]{3}{*}{$\mathrm{X}(\mathrm{m} \Omega)$} & 1.8 & 0 & 0.6 & 0 & 3.7 & 0 & 0.7 & 0 \\
\hline & \multicolumn{2}{|c|}{ L9a } & \multicolumn{2}{|c|}{$\mathrm{L} 9 \mathrm{~b}$} & \multicolumn{2}{|c|}{ L10a } & \multicolumn{2}{|c|}{$\mathrm{L} 10 \mathrm{~b}$} \\
\hline & $\mathrm{Ph}$ & $\mathrm{N}$ & $\mathrm{Ph}$ & $\mathrm{N}$ & $\mathrm{Ph}$ & $\mathrm{N}$ & $\mathrm{Ph}$ & $\mathrm{N}$ \\
\hline $\mathrm{R}(\mathrm{m} \Omega)$ & 3.8 & 7.6 & 3.6 & 7.1 & 10.7 & 21.4 & 3.8 & 7.6 \\
\hline \multirow[t]{3}{*}{$\mathrm{X}(\mathrm{m} \Omega)$} & 0.9 & 0 & 0.9 & 0 & 2.7 & 0 & 1 & 0 \\
\hline & \multicolumn{2}{|c|}{ L11a } & \multicolumn{2}{|c|}{ L11b } & \multicolumn{2}{|c|}{ L12 } & & \\
\hline & $\mathrm{Ph}$ & $\mathrm{N}$ & $\mathrm{Ph}$ & $\mathrm{N}$ & $\mathrm{Ph}$ & $\mathrm{N}$ & & \\
\hline $\mathrm{R}(\mathrm{m} \Omega)$ & 26.7 & 42 & 3.8 & 0.6 & 21.4 & 42.9 & & \\
\hline $\mathrm{X}(\mathrm{m} \Omega)$ & 6.7 & 0 & 1 & 0 & 5.4 & 0 & & \\
\hline
\end{tabular}

TABLE IV: Power losses and efficiency for different cases

TABLE II: Line characteristics

\begin{tabular}{||c|c|c|c|c|c|c|c||}
\hline & L1 & L2 & L3 & L4a & L4b & L5a & L5b \\
\hline $\mathrm{S}_{\mathrm{PH}}\left(\mathrm{mm}^{2}\right)$ & 95 & 150 & 150 & 240 & 240 & 240 & 240 \\
\hline $\mathrm{S}_{\mathrm{N}}\left(\mathrm{mm}^{2}\right)$ & 90 & 95 & 95 & 120 & 120 & 120 & 120 \\
\hline Length (m) & 15 & 35 & 20 & 60 & 20 & 125 & 22 \\
\hline \hline & L9a & L9b & L10a & L10b & L11a & L11b & L12 \\
\hline $\mathrm{S}_{\mathrm{PH}}\left(\mathrm{mm}^{2}\right)$ & 240 & 240 & 240 & 240 & 150 & 150 & 240 \\
\hline $\mathrm{S}_{\mathrm{N}}\left(\mathrm{mm}^{2}\right)$ & 120 & 120 & 120 & 120 & 95 & 95 & 120 \\
\hline Length (m) & 32 & 30 & 90 & 32 & 140 & 20 & 180 \\
\hline
\end{tabular}

\section{Simulation results}

Each of the VSI connected in parallel with each of the loads shown in Fig. 4 is programmed to compensate the different non active currents consumed by the load. Table IV shows the results in terms of power losses and efficiency of the low voltage system for different cases considering the different current components compensated by the inverters.

Table $\mathrm{V}$ shows the effective value of the currents injected by the VSI for cases 2, 3 and 4 as a percentage of the

\begin{tabular}{|c|c|c|c|}
\hline $\begin{array}{c}\text { Current } \\
\text { component } \\
\text { compensated }\end{array}$ & $\begin{array}{c}\text { Loads } \\
\text { total power } \\
(\mathrm{kW})\end{array}$ & $\begin{array}{c}\text { Total losses } \\
(\mathrm{kW})\end{array}$ & $\begin{array}{c}\text { Efficiency } \\
(\%)\end{array}$ \\
\hline Case1: None & 614.2 & 11.93 & 98.1 \\
\hline Case 2: $\mathrm{I}_{\mathrm{r}}$ & 610.5 & 7.6 & 98.76 \\
\hline Case 3: $\mathrm{I}_{0}$ & 614.9 & 10.8 & 98.27 \\
\hline Case 4: $\mathrm{I}_{-}$ & 613.5 & 11.81 & 98.11 \\
\hline Case 5: $\mathrm{I}_{\mathrm{r}}, \mathrm{I}_{0}$ & 611.5 & 6.93 & 98.88 \\
\hline Case 6: $\mathrm{I}_{\mathrm{r}}, \mathrm{I}_{-}$ & 610.5 & 7.59 & 98.77 \\
\hline Case 7: $\mathrm{I}_{-}, \mathrm{I}_{0}$ & 614.9 & 10.59 & 98.31 \\
\hline
\end{tabular}

nominal current of the inverters $(72 \mathrm{~A})$. When compensating the reactive component, it can be seen that in some cases, the inverters should inject a higher current than the nominal value.

As shown in Table IV, the compensation of the reactive component produces the highest decrease in the power losses. However, for that purpose, the inverters need, as shown in Table V, most of their current capacity due to the high value of the reactive currents. Obviously, the use of VSI may not be the least cost system to compensate the reactive power in an electrical system.

The compensation of the zero sequence component results to be the most effective way to reduce power 
losses as theoretically expressed by equation (4). Just in four inverters the current capacity needed for its total compensation exceeds one third of their capacity. In the simulated network, the total compensation of this component increases the system efficiency in a $0.17 \%$. Additionally, the reduction of this component reduces the voltage unbalance at the loads.

Finally, the compensation of the negative sequence current component has a very small influence in the power losses in a real system. However, it could be interesting to compensate this component when the voltage unbalance at the load can reach a high value, i.e. higher than $5 \%$.

TABLE V: Required current capacity of the VSI (\%)

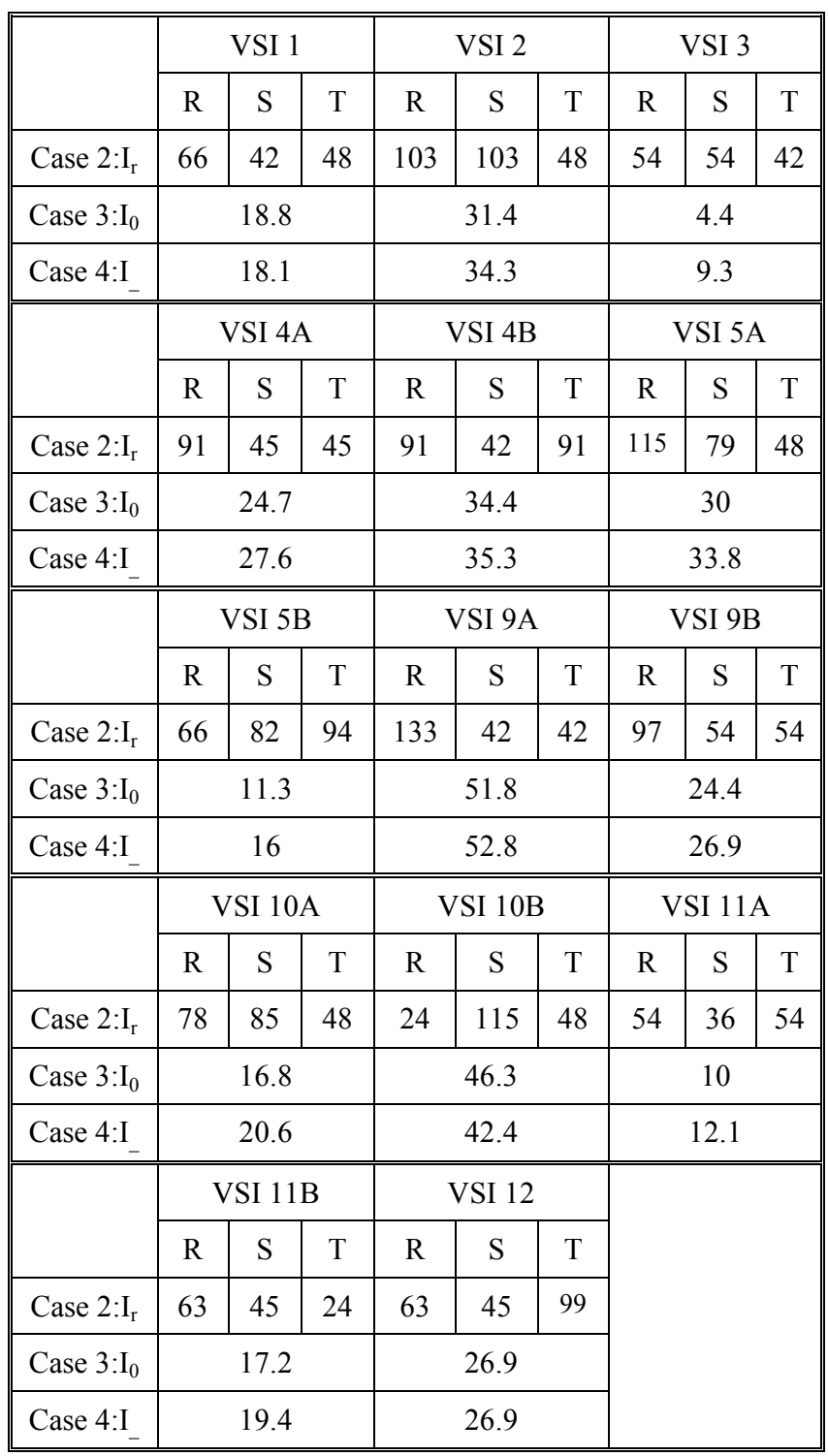

\section{Conclusions}

The VSI associated to DG in low voltage networks can be used, in a multi-functional approach, to implement different operation and control functions tat can enhance the performance of the distribution grid. Particularly, the DG can be used to increase the power quality and the efficiency of the network when there is a remaining power capacity in the inverters.

The benefits of compensating the non active current components have been analysed and quantified through the simulation of a typical urban low voltage distribution network with a large penetration of DG. It can be concluded that the first component to be partially or totally compensated should be the zero sequence current as it produces the highest losses reduction per unit of current. A relatively significant increase in the system efficiency has been found. Additionally, the VSI could be used to reduce the reactive and negative sequence components of the load currents although their influence in power losses reduction is quite small per unit of current.

The implementation of the proposed compensation functions requires the use of new topologies for the inverters with some small changes with respect to the topologies currently in use. New current control algorithms should also be implemented. A hysteresis current control mode is considered to be the most simple and effective control system for this kind of applications.

\section{Acknowledgement}

This work was supported by the Institut de la Petita i Mitjana Industria de la Generalitat Valenciana (IMPIVA) and the European Union.

\section{References}

[1] T. Ackermann, G. Andersson and L. Soder, "Distributed generation: a definition," Electr. Power Syst. Res., vol. 57, pp. 195-204, 4/20. 2001.

[2] R. H. Lasseter, "Control of distributed resources," Bulk Power System Dynamics and Control IV, August 23-28, 1998, pp323-329.

[3] Tran-Quoc T., Andrieu C., Hadjsaid N.: Technical impacts of small distributed generation units on LV networks, IEEE Power Engineering Society General Meeting, 2003, Vol 4.

[4] Singh B., Al-Haddad K., Chandra A.: A Review of Active Filters for Power Quality Improvement, IEEE Trans. Ind. Electronics, vol. 46, pp.960-971, Oct 1999.

[5] D. M. Brod, D. W. Novotny, "Current control of VSI-PWM Inverters", Industry Applications, IEEE Transaction on, vol. IA-21, No 4, May/June 1985

[6] F. Blaabjerg, R. Teodorescu, M. Liserre, A. V. Timbus, "Overview of control and grid synchronization for distributed power generation systems" Industrial Electronics, IEEE Transaction on, vol. 53, No 5, October, 2006.

[7] Quinn C. A., Mohan N.: Active filtering of harmonic currents in three-phase, four-wire systems with three-phase, single-phase nonlinear loads, Proc. IEEE APEC'92, 1992, pp. 829-836. 